\title{
EL PAPEL DE LA MATERNIDAD EN LA MUJER
}

Enriqueta Moreno Orúe

El papel otorgado a la mujer como conservadora de la especie ha hecho de la maternidad una constante en la historia de la humanidad, cuyo testimonio queda plasmado en los mitos, representaciones y ritos que dan cuenta de una evolución de las fantasías relativas a la fecundidad y la concepción. La idealización del misterio de la gestación y de la procreación ha suscitado comportamientos míticos en todas las culturas: son la expresión del miedo inconsciente y la angustia ante el misterio de la vida y de la muerte, cuya emergencia se sitúa en el interior de la mujer, ese interior al que Freud negaba representación en el inconsciente. Pantalla oscura donde se proyecta el poder de decidir sobre el embrión, destruirle o darle posibilidad de vivir, ésta es la relación mas asimétrica por la que pasa la humanidad, el exponente dramático de la indefensión absoluta. Desde esa realidad abrumadora se instaura la figura mítica de la mujer. Ella es el receptáculo de la omnipotencia, el objeto necesitado, amado, odiado, es el misterio y la evidencia, la tranquilidad y el desasosiego. Su imponente imagen aparece representada desde la antigüedad como una figura majestuosa, llena de atributos de poder y fertilidad.

Figura fantasmática universal, propiciada desde la prematuridad de la criatura humana, pantalla donde se proyectan anhelos de completud , fetiche que inquieta y remite a ese lugar inombrable del espectro humano, espejismo de aquel deseo de completud cuya fisura se perpetúa en la existencia.

Esta figura femenina mítica y emblemática, arcaica en sus contenidos y representaciones, podríamos considerarla como una de las caras que componen esa compleja macla que cristaliza en el "ser de mujer”.

Parecería que esa faceta arcaica ha quedado sumergida en el inconsciente y que en 
el devenir histórico de la mujer, las otras caras de la macla perfilan una imagen justamente opuesta: Ella es la carencia.

¿Dónde podemos pues situar a la mujer, entre esos dos polos: el de la omnipotencia y completud y el de la castración, sin que sufra una deformación que distorsiona lo más genuino de su condición femenina?

La castración en la mujer no es consecuencia de su identidad sexual sino de su condición humana: al igual que en el hombre, ambos están sujetos al inevitable "infortunio” del que hablara Freud. En este sentido es importante recordar el equívoco que existe cuando se habla de lo natural o instintivo en el ser humano, hecho frecuente al referirse a la maternidad, como si algo del orden de lo instintivo fuera determinante del deseo.

La complejidad de estructuras a nivel evolutivo que caracteriza a la especie humana produce un cambio cualitativo que le aleja de los parámetros biológicos finales, propios de otras especies, para acceder a una modalidad de parámetros abiertos, donde se inscribe el funcionamiento mental y psíquico y en consecuencia la capacidad de representación, simbolización y lenguaje que sitúa al hombre como sujeto psíquico. A partir de ahí, el deseo y su representación marcan la fisura permanente con la realización plenamente satisfactoria del mismo. Esta fisura es fundamental para entender el destino del ser en cualquiera de sus manifestaciones. La que hoy nos ocupa es la MATERNIDAD.

Maternidad y feminidad parecen estar unidas inexorablemente y, sin embargo, no es exactamente así, puesto que la feminidad se refiere a una modalidad esencial del psiquismo de la mujer que engloba un conjunto de representaciones y afectos, algunos de los cuales están ligados al cuerpo y al espacio interno del mismo, a sus funciones y satisfacciones narcisistas derivadas de dichas representaciones. Lo femenino no se reduce a lo maternal, éste queda incluido en aquél, trasciende a la realización concreta, biológica de la maternidad, pues la mujer es madre en su funcionamiento mental y psíquico, es la parte disponible para la vida, es la capacidad de esperar, recibir, contener y desprenderse. 
La mujer es tránsito de unión y separación, espacio abierto del sexo femenino, expectante del deseo propio y ajeno, dependiente de éste. Interior femenino donde los goces y los duelos se suceden y la temporalidad marca su historia, discontinuidades evolutivas por las que transita su propio cuerpo, modificándose en un destino de identidades que ponen en juego la capacidad creativa de poder seguir-siendo reconocible para sí en la discontinuidad de su existencia.

La teoría psicoanalítica sostiene que ni el determinismo biológico ni el social definen de manera convincente la identidad del ser, porque la realidad corporal, por evidente que sea, se transforma, no obstante, en la representación subjetiva del propio cuerpo. Metamorfosis que el símbolo propicia resignificando una identidad más allá de la anatomía y sus funciones propias, para establecer a través de la historicidad del sujeto, el asentamiento de una subjetividad vivencial traspasada por vínculos humanos presentes desde el nacimiento.

La anatomía no determina el destino, lo condiciona, se nace varón o hembra pero se deviene hombre o mujer. Freud en 1932 decía: "El psicoanálisis por su naturaleza no pretende describir qué es la mujer, sino indagar cómo deviene”.

Hay un nexo en la historia del psicoanálisis que une sus orígenes al tema de la feminidad. Freud estaba fascinado por su misterio, pero al mismo tiempo sentía miedo por su fascinación, tal como lo demuestran las metáforas para designar los genitales femeninos: representan el vacío, la carencia, el continente oscuro, el enigma... El tema de la mujer se le ocultó de manera tan particular que le hizo decir: "Las mujeres sois vosotras mismas tal enigma".

Más de cien años nos separan de los primeros estudios de Freud sobre la histeria y todavía los psicoanalistas parecemos condenados a repetir lugares comunes como la castración y el falo, damos vueltas a un laberinto sin encontrar otra salida que la lectura desde lo falocéntrico en la cual Lacan es un estilista.

Freud hace una lectura de la feminidad desde el síntoma, soslaya pues la lógica 
articulación que contempla la natural conflictividad del ser, de tal forma, que ese "querer de mujer” al que Freud calificó de enigma cuestiona el saber psicoanalítico.

La relación de Freud con la mujer está presente de manera más o menos implícita a lo largo de su obra. En 1884, percibía a la mujer como un secreto por descubrir: la histeria es la historia del psicoanálisis y de Freud; su error fue utilizar un instrumento inadecuado para tal descubrimiento. A semejanza de Yahvé, que crea a Eva a partir de una costilla de Adán, Freud derivó su teoría del desarrollo psicosexual de la niña a partir de la psicosexualidad masculina, en la que afirma una serie de supuestos teóricos que evidentemente tienen su fundamento en una fantasía defensiva infantil en cuanto al interior de la mujer y sexualidad de la madre, como posteriormente ha demostrado la clínica, tanto en el tratamiento de niños y niñas como en el de adultos de ambos sexos.

Sostener que la diferencia entre el hombre y la mujer reside en tener o no tener pene conduce al establecimiento del sexo femenino como castrado. La "falta" se erige en una defensa contra el saber de la existencia de aquello que la madre posee, pues remite a la sexualidad de los padres, excluyendo de manera especial tanto al niño como a la niña por su incapacidad de colmar el deseo de la madre como sujeto sexuado. Ésta es la primera Ley que el sujeto asume como castración, la “Ley de la Imposibilidad”, marcada por la mujermadre, que precede a la "Ley de la Prohibición”, marcada por el padre, esto es, la "Ley Edípica”.

Para Freud, la niña es un ser castrado, “falta” en lo real, no del orden simbólico; desde este supuesto su desarrollo psicosexual estará marcado por un déficit eleborativo del complejo de Edipo y de castración, así como del establecimiento del Super-Yo, capacidad de sublimación y amor objetal. La modalidad de sus vínculos afectivos se caracteriza por la rivalidad fálica y el narcisismo. El deseo del hijo proviene de su deseo de poseer un pene.

Suele decirse que Freud define a la mujer desde una categoría construida culturalmente. Opino que esto es una verdad parcial. Ciertamente que el pensamiento es en parte subsidiario de su época, pero en el tema que nos ocupa se añaden las propias 
El papel de la maternidad en la mujer

dificultades de Freud con respecto a la mujer, cuestión que él mismo no oculta a lo largo de sus escritos. En su obra pueden percibirse dos etapas: una que comprende de 1890 a 1920, en la que se destaca su trabajo con las histéricas, es decir, la mujer en el síntoma y en la resistencia a la cura; y la segunda etapa, de 1920 hasta sus últimos trabajos, cuando se esfuerza por descifrar ese querer de mujer que le daría la clave para descifrar el enigma.

Freud está perplejo, en 1930 confiesa que no sabe más y que lo dicho hasta entonces es insatisfactorio, entonces se dirige a las mujeres, a los poetas y a la ciencia para que averigüen lo que para él es una roca inexpugnable. Pero al mismo tiempo Freud justifica su "no saber” por haber subestimado el vínculo primario de la niña con la madre, territorio que se adentra en ese otro mundo del “arcaico femenino”, el que Freud trató de evitar con su teoría del desarrollo psicosexual infantil. El retorno de lo reprimido se impone al honesto científico, ya en edad avanzada, en esa época de la vida en que se comienza a perder el miedo a tantas cosas, porque hay una que las eclipsa por evidente: la muerte. Freud puede acercarse a la mujer y con ello deja una vía abierta que cuestiona aspectos importantes de su teoría psicoanalítica.

Adentrándonos por esa vía, vamos a considerar el deseo del hijo en la mujer.

En primer término, hemos de tener en cuenta que la feminidad ha sido definida desde una cultura de dominio masculino (me refiero a la cultura occidental) mediatizada por la influencia del pensamiento judeo-cristiano, donde el status de la mujer ha sido y es manipulado de forma artificial dentro del contexto socio-cultural por medio de ideologías que conducen a la adscripción de roles adscritos a la identidad sexual, donde se perfila la dialéctica entre lo que el "ser es” y la expectativa de lo que “debe llegar a ser”. Esta expectativa es de tal importancia para el individuo que produce un eclipse en la aparición y desarrollo de aspectos propios, valiosos, porque no responden al orden del discurso social imperante.

El mismo Freud señalaba que debemos cuidarnos de no pasar por alto la influencia de las normas sociales. 
El deseo de la mujer ha entrado a formar parte de esa manipulación que abarca un amplio espectro, desde relegarla en el terreno de la sexualidad a entronizarla en la función materna.

Es a partir del siglo XIX cuando se produce una exaltación cada vez mayor de la maternidad y del espíritu de abnegación y sacrificio como prebenda de la madre de familia: ella, LA MADRE, con mayúsculas, está destinada a “vivir para y por los demás”, ésta es su gran misión y su pedestal, ése que le impide bajar a ocupar otros lugares.

No se cuestiona si la mujer desea ser madre, ella es madre por decreto y apelando a lo biológico se dice de la maternidad que es instintiva, por tanto es contra-natura no anhelar el hijo; en última instancia se considera una perversión, en el sentido de pervertir el orden de la naturaleza.

Bajo la influencia de estos esquemas, el deseo de ser madre queda atrapado en un imperativo social que deviene el Ideal del Yo, colapsando la posibilidad de una opción en la que los componentes libidinales predominen sobre los ideales sociales.

Anteriormente he señalado cómo la complejidad de estructuras y funciones propias de nosotros los humanos es el resultado de una evolución que nos aleja de lo instintivo como determinante del comportamiento, promoviendo el acceso a un orden diferente: la representación del deseo, que siempre es referencia a un símbolo en tanto que completa lo que en la realidad falta.

De ahí el deseo del hijo, el deseo de ser madre que se gesta en las encrucijadas de un “devenir mujer” bajo la primacía de identificaciones desde épocas muy tempranas y de vínculos afectivos que subyacen a las mismas.

Estas encrucijadas, pasajes forzosos en el destino de mujer, impiden simplificar el hecho de la maternidad y el deseo del hijo como un asunto puramente "natural” en la mujer. El deslizamiento hacia lo biológico es un alivio que evita la perplejidad que todo conocimiento suscita, pues una vez que se sabe que no se sabe, el interrogante es un reto a investigar. 
El romance edípico en la niña es un texto a esclarecer en la teoría psicoanalítica: hay un resto todavía inédito, objeto de controversia entre psicoanalistas; en ese resto se oculta tal vez el obscuro objeto del deseo femenino.

Freud dice que para entender a la mujer hay que investigar acerca del vínculo primario con la madre, esa pasión primitiva que afecta a los dos sexos, pasión ligada a la vida y al desamparo, pasión ignorada que la represión ordena silenciar, innombrable en toda su dimensión. La niña librada al amor de la madre como inevitable destino de toda criatura humana tiene que ser capaz de romper ese destino, a diferencia del niño que tiene fijo su recorrido amoroso. Ella, como una heroína de la tragedia griega, tiene que escapar de ese lugar que amenaza su por-venir de mujer y, errante, buscar un nuevo contenido a su continente de amor. Pero, ¿realmente resigna ese amor sin salida? ¿O va a transitar de por vida con la reliquia de un resto de ese amor? El padre, ¿¿es el sustituto de un amor vacante? ¿O el padre es el resultado de un cambio en la elección de objeto amoroso? Y ese cambio, ¿en función de qué se establece?, ¿qué mecanismos psíquicos entran en juego en esa nueva orientación de la libido?

Tal vez apelando a la economía narcisista podamos entrever el deseo edípico en la niña para salir de un drama de amor silencioso, indiferenciado, sin narrativa y acceder a la tragedia pasional de un amor prohibido cuya ley la diferencia psicosexualmente, es decir, la inicia en el juego mediático de la diferenciación sexual, la prohibición establece el reconocimiento de su condición de mujer, comienza la gestación del hijo imaginario, como alternativa a la pérdida de su condición de niña-con-mamá.

El devenir-porvenir de mujer se inicia con un duelo referido a una pérdida fundamental, a ese amor sin salida del vínculo materno, abandono que perfora su experiencia afectiva, oquedad sin nombre en busca de un objeto que lo suture. ¿El hijo imaginario será el encargado de llenar ese vacío sin nombre? La unión con el feto permite a la mujer una re-fusión con el cuerpo materno en la doble identificación de bebé-y-madre, lo 
que conduce a reanudar los lazos con el primer objeto de la pulsión. Freud dice que la identificación es una modalidad de conservar el objeto perdido. ¿El hijo viene a cumplir esa función? ¿Es por identificación con una parte de sí misma, su parte niña unida a la madre? Y, a la vez ella madre, ¿¿se identifica con la madre perdida, idealizada, la madre objeto de su pulsión? El hijo también constituye parte de la fantasía edipíca cuya remimiscencia toma expresión en la pareja parental del presente. Soy de la opinión de que el edipo no se disuelve, quedan restos que no patologizan los vínculos del presente, re-crean libidinalmente una historia que ha devenido metáfora, a la manera como Winnicott trata el juego.

El hijo satisface, en algunos casos, demandas que provienen del Ideal del Yo. La idea del niño como falo de la madre no da cuenta de la complejidad de las fantasías sobre su propio interior y del hijo imaginario como portador emblemático del conflicto edípico. La identificación con la función femenina como logro en la integración de identificaciones femeninas y masculinas sólo es posible dentro del marco de la organización edípica y de la apertura al deseo dirigido al padre como pasaje a la heterosexualidad.

Estas y otras hipótesis posibles muestran el irrelevante papel del instinto en el deseo del hijo en la mujer.

La maternidad es consustancial a la psicosexualidad femenina, lo cual no es equivalente a suponer el deseo universal de ser madre.

El embarazo se suele considerar como un estado de plenitud-completud, como un logro para la mujer, obviando la crisis psicosomática que le acompaña debido a cambios esenciales que afectan tanto a la modificación del esquema corporal como metabólicos, endocrinos, neurovegetativos, con su repercusión en el sistema nervioso central, además de los relativos a las fantasías inconscientes y conscientes como correlato psíquico de esos cambios y en función de la crisis de identidad con el advenimiento a “ser-madre”, debido a que se reactivan, regresivamente, vínculos y fantasías primarias en relación con la historia personal. Sería prolijo dar cuenta de todas las manifestaciones psicosomáticas que hablan 
El papel de la maternidad en la mujer

del trabajo no solo físico sino y sobretodo psíquico que realiza la mujer durante el periodo de gestación.

El embarazo modifica la relación de la mujer con su propio cuerpo, su interior cobra un protagonismo insólito, algo esencial está sucediendo: “un ser se está haciendo dentro de mí, lo siento como mío pero sé que está destinado a no ser yo”. La experiencia de la maternidad le pone en evidencia que su destino de madre es dar, reproducir, crear y recrear objetos de amor que continuamente se escapan.

Siempre produce asombro la confirmación de un embarazo aún en el caso de ser calculado con la mayor precisión, lo cual no deja de ser significativo. Mucho podría comentarse sobre ello pero lo cierto es que a lo largo del periodo de gestación se van produciendo cambios, en general adaptativos. El vínculo de la madre con la criatura alojada en su interior se va reforzando progresivamente, entablándose un diálogo intimista con ese conocido-por-conocer que lleva dentro de sí. Un mundo de fantasías en torno a él la acompañan hasta el momento del parto en que se produce una inflexión, como una gran conmoción, preludio del gran acontecimiento que separa al hijo del cuerpo de la madre, experiencia inefable para la madre, esfuerzo titánico compartido asimétricamente con su bebé. Momento cumbre de unión-separación, nacimiento del hijo y de la mujer-madre. Intrincación pulsional que en esos momentos alcanza su máximo nivel, la pulsión de vida domina la situación, pero las fantasías de muerte están presentes como las hadas maléficas de los cuentos. Retorno de angustias muy primitivas: temor a desfallecer, a romperse, deshacerse, dificultades de límites en lo corporal entre el hijo y ella misma. La expulsión en el parto configura una experiencia en que se alternan sensaciones de plenitud y de vacío que remiten a las fantasías inconscientes de la primera infancia con respecto al interior de niña: lleno o hueco, valioso o insignificante. Se conmueven los objetos internos infantiles y la Madre, siempre la Madre, ese vínculo indestructible a nivel inconsciente, está presente y con ella aparecen otros personajes, los significativos de la infancia, incluida su parte niña que asiste asombrada ante tal acontecimiento: todos ellos se mueven en el escenario del 
inconsciente. Mientras, en el paritorio se desarrolla otra escena: una cabecita asoma por la cavidad materna, en un último esfuerzo ella le empuja separándolo de sí, ayudándole a desprenderse de ese lugar sin retorno. Por fin la señal tan anhelada: un niño llora, su primer llanto es un canto a la vida.

Con su venida al mundo, con su presencia real, muere el hijo imaginario, el hijo de sus fantasías, las que le han acompañado durante el periodo de gestación, tiene que desalojarlo para abrir un espacio de ensoñaciones, proyectos, fantasías, expectativas a este hijo definido en lo real.

Doble duelo el de la madre: en su cuerpo, porque algo suyo se ha desprendido de sí, en lo imaginario por la pérdida de una fantasía, que como tal se presta a diversas representaciones. Ahora se enfrenta a la demanda imperiosa de un bebé real que la necesita para vivir.

La depresión que acompaña al post-parto, me refiero a la depresión normal, es consecuencia de todas esas turbulencias somato-psíquicas, coexisitiendo con las satisfacciones y el placer derivado de un incremento de la libido, del amor objetal y del narcisismo. La gravedad que a veces alcanza, en las llamadas psicosis puerperales, se debe a la presencia de graves conflictos psíquicos, a veces latentes, que emergen en momentos de crisis o cambios que, al no poder elaborarse, se transforman en catastróficos y enloquecedores.

A continuación voy a esbozar una serie de cuestiones que pueden ser objeto de interés en futuras investigaciones: ¿Por qué la función materna ha tenido y tiene un lugar prioritario sobre otras como por ejemplo: la sexualidad, la participación en la cultura y el mundo del pensamiento o la de actividades sociales altruistas? ¿A qué se debe el establecimiento de una jerarquización en el supuesto deseo de la mujer y no se contempla una articulación de deseos? ¿Es el imperativo socio-cultural el que da prioridad a la función re-productora en la mujer, siendo asumida esta ideología por el colectivo femenino durante siglos? 